\title{
Dealing with a stenotic bicuspid aortic valve: Is this still an off-label procedure for a sutureless valve?
}

\author{
Mattia Glauber, MD, Matteo Ferrarini, MD, Antonio Lio, MD, and Antonio Miceli, MD, PhD
}

\footnotetext{
From the Istituto Clinico Sant'Ambrogio, University and Research Hospitals, Gruppo Ospedaliero San Donato, Milano, Italy.

Disclosures: MG and MF have received a proctorship and lecture fees from Sorin. All other authors have nothing to disclose in regard to commercial support.

Received for publication July 14, 2015; accepted for publication July 14, 2015; available ahead of print Aug 12, 2015.

Address for reprints: Mattia Glauber, MD, University and Research Hospitals, Istituto Clinico Sant'Ambrogio, Gruppo Ospedaliero San Donato, Via Faravelli 16, 20100 Milano, Italy (E-mail: mattia.glauber@ftgm.it) J Thorac Cardiovasc Surg 2015;150:858-9

$0022-5223 / \$ 36.00$

Copyright (C) 2015 Published by Elsevier Inc. on behalf of The American Association for Thoracic Surgery http://dx.doi.org/10.1016/j.jtcvs.2015.07.049
}

Bicuspid aortic valve (BAV) is the most common and oldest known congenital disease of the human heart. BAV occurs in $1 \%$ to $2 \%$ of live births and was first described by Leonardo da Vinci in one of his sketches in the 16th century. ${ }^{1}$ This valve is typically made of 2 unequally sized leaflets, often associated with 1 raphe positioned between the left and right coronary sinuses and 3 sinuses of Valsalva (type 1 Sievers). In only $5 \%$ of cases, the leaflets are symmetric, presenting with no raphe and 2 identifiable sinuses of Valsalva (type 0 or pure bicuspid valve). ${ }^{2}$ Because of the anatomic leaflet alteration, severe aortic stenosis often may occur. In this regard, aortic valve replacement using a stented valve is the conventional approach in the treatment of a severe stenotic for BAV. Of note, it has been estimated that more than $50 \%$ of all valve replacement surgeries for aortic valve stenosis can be attributed to BAV disease. ${ }^{3}$

Sutureless technology has been developed as an alternative to stented biological valves in intermediate and highrisk patients undergoing aortic valve replacement to simplify and standardize the surgical procedure and reduce the ischemic times. ${ }^{4}$ However, BAV always has been considered a contraindication for the implantation of a sutureless bioprosthesis because of its different anatomic aspects of the aortic root in terms of annulus geometry (more elliptic), sinus asymmetry, and leaflet commissures, which often have different heights, especially in the presence of pure BAV. In this issue of the Journal, Nguyen and colleagues ${ }^{5}$ retrospectively evaluated the feasibility and perioperative outcomes of sutureless aortic valve replacement in patients with BAVs and aortic stenosis. Specifically, 25 patients with BAVs received a Perceval S sutureless valve (Sorin, Milan, Italy). The main outcomes evaluated are in line with previous studies. 6,7 One patient died after surgery, and overall 1-year survival was $88 \%$. Neither migration nor structural damage occurred at follow-up, and only 3 patients had a trace of paravalvular leakage. The rate of pacemaker disturbance.

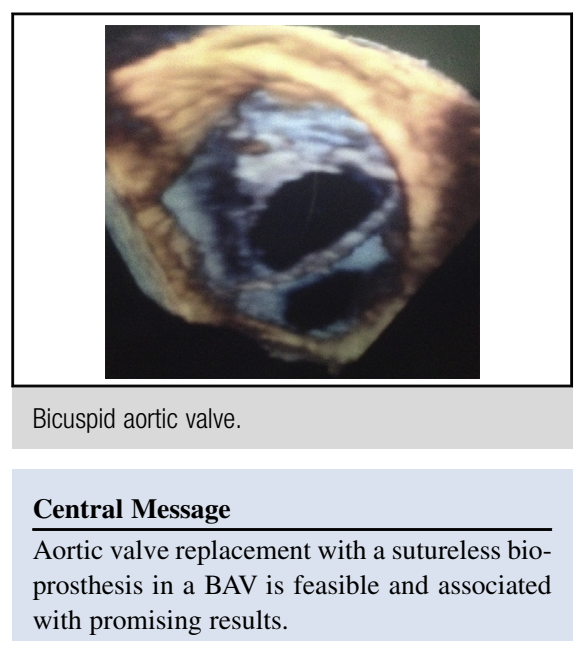

See Article page 851 .

implantation was higher than that reported by others; however, this is multifactorial and depends on the preoperative rhythm condition, annulus decalcification, and local factors, such as the proactivity of the electrophysiologists to implant a pacemaker after a new electrical

The most important aspect of this report is the technical implantation of the Perceval $\mathrm{S}$ valve in a BAV. The 2 key points for a perfect sealing of the Perceval to a bicuspid aortic annulus are the circularity of the aortic annulus and the equality of heights of the leaflet commissures. Because of the anatomic asymmetry of the BAV, Nguyen and colleagues $^{5}$ suggest recreating 3 natural nadir points positioned at 120 degrees with the aim of recreating a circular annulus. However, this technique is valid only in the presence of BAV with 3 sinuses of Valsalva (type I). Conversely, no information is reported regarding the other types of BAV. According to our experience to avoid valvular dislocation and paravalvular leakage, a commissural plication is often required to restore the circularity of the aortic annulus, especially when the commissures are placed at different heights. Normally, the Perceval S sutureless valve is well positioned when the inflow ring covers the aortic annulus, including the intercommissural triangles. If the height of one of the intercommissural triangles is higher than the inflow ring, the annulus is not covered and a paravalvular leakage may occur. In this case, the plication of all intercommissural triangles at their basis reports the commissure at the same heights; the 
annulus becomes circular and is fully covered by the inflow ring of the prosthesis. Last, a thorough decalcification of the aortic annulus is recommended to restore its elasticity and adaptability to the newly implanted prosthetic valve. Once the prosthesis is released into the aortic annulus, a correct position of the prosthetic valve is reached in the presence of a perfect symmetry and coaptation of the neoleaflets (Mercedes-Benz sign). With their study, Nguyen and colleagues ${ }^{5}$ have demonstrated that BAV is no longer a contraindication for the implantation of a Perceval S sutureless valve. Nevertheless, we recommend performing this technique only after gaining confidence with the implantation of the Perceval $S$ in the tricuspid aortic valve. Although this is still an off-label procedure, once the aortic annulus becomes circular, aortic valve replacement with a sutureless valve is feasible and associated with encouraging results. However, more data are required to confirm these results.

\section{References}

1. Friedman T, Mani A, Elefteriades JA. Bicuspid aortic valve: clinical approach and scientific review of a common clinical entity. Expert Rev Cardiovasc Ther. 2008;6: 235-48.

2. Siviers HH, Schmidtke C. A classification system for the bicuspid aortic valve from 304 surgical specimens. J Thorac Cardiovasc Surg. 2007;133:1226-33.

3. Michelena HI, Prakash SK, Della Corte A, Bissel MM, Anavekar N, Mathieu P, et al. Bicuspid aortic valve. Identifying knowledge gaps and rising to the challenge from the international bicuspid aortic valve consortium (BAVCon). Circulation. 2014;129:2691-704

4. Miceli A, Santarpino G, Pfeiffer S, Murzi M, Gilmanov D, Concistrè G, et al Minimally invasive aortic valve replacement with Perceval S sutureless valve: early outcomes and one-year survival from two European centers. J Thorac Cardiovasc Surg. 2014;148:2838-43.

5. Nguyen A, Fortin W, Mazine A, Bouchard D, Carrier M, El Hamamsy I, et al Feasibility and outcomes of sutureless aortic valve replacement in patients with bicuspid aortic valves. J Thorac Cardiovasc Surg. 2015;150:851-7.

6. Shresta M, Fischlein T, Meuris B, Flameng W, Carrel T, Madonna F, et al. European multicentre experience with the sutureless Perceval valve: clinical and haemodynamic outcomes up to 5 years in over 700 patients. Eur J Cardiothorac Surg. 2015; http://dx.doi.org/10.1093/ejcts/ezv040.

7. Folliguet TA, Laborde F, Zannis K, Ghorayeb F, Haverich A, Shrestha M. Sutureless Perceval aortic valve replacement: results of two European centers. Ann Thorac Surg. 2012;93:1483-8. 